\title{
Bomba acionada por um rotor Savonius submerso
}

John H. Harwood (')

Ronaldo de Almeida ${ }^{2}$ ]

\section{Resumo}

A construção de uma bomba de água acionada por correntezas de rios mediante um rotor Savonius submerso está descrita em detalhe. O desenho da bomba é muito simples, de maneira que a construção pode ser feita por qualquer pessoa usando ferramentas manuais. O custo de materiais para fazer uma bomba é de USS 70,00 . Há uma leve variação no desempenho de bombas deste tipo devida à construção artesanal. Contudo uma bomba desenvolvendo potência máxima instalada num local com uma correnteza de 0,6 m.seg.-1 $(2,2 \mathrm{~km} / \mathrm{h})$ jogou 2100 litros de água por dia a uma altura de $28 \mathrm{~m}$ e uma outra bomba instalada num local com uma correnteza de $1,1 \mathrm{~m} . \mathrm{seg}^{-1}(4,0 \mathrm{~km} /$ h) jogou 3100 litros de água à mesma altura. Com pressōes menores a vazão aumentou até a faixa de 3500 até 3900 litros por dia. Como a bomba fode proforcionarconforto ao morador ribeirinho $\mathrm{e} / \mathrm{ou}$ fornecer água para outras finalidades, é de esperar-se que o desenho seja divulgado ativamente. Contatos com entidades governamentais vêm sendo desenvolvidos com esta finalidade.

\section{INTRODUÇÃo}

Em trabalho anterior, Harwood (1980) mostrou que era possível extrair energia de correntezas de rios usando-se rotores de baixo custo. Um dos rotores testados no referido trabalho foi o rotor Savonius, feito de um tambor de óleo, cortado. O autor concluiu que em rios como o Solimões este rotor podia desenvolver suficiente potência para bombear água para casas ribeirinhas.

Baseada nesta conclusão, uma bomba acionada por um rotor Savonius foi construída e modificada progressivamente até chegar ao desenho descrito abaixo que é simples, robusto e prático.

A unidade fiutua, acompanhando assim as variações anuais do rio e está normalmente ancorada no local por um só cabo.

\section{MATERIAIS E MÉTODOS}

O "motor" da bomba é um rotor Savonius feito de um camburão de óleo padrão (200 litros) cortado longitudinalmente em duas partes iguais como descrito por Harwood (1980) . $O$ rotor fica suspenso completamente submerso em baixo de um flutuador, com o seu eixo horizontal e perpendicular à correnteza. Como o rotor desenvolve dois tempos de força por rotação, ele aciona duas bombas defasadas de $180^{\circ}$, uma em cada extremidade do seu eixo.

A lista de todos os materiais para a construçäo de uma bomba está na tabela 1. O custo do total destes materiais está em torno de USS 70,00 por bomba. A construção da bomba está mostrada nos desenhos (Fig. 8-10) e nas fotografias (Fig. 1-7). Um detalhe que precisa ser salientado é que em vista lateral (Fig. 8) o ângulo entre o raio do virabrequim e o diâmetro em que o barril foi cortado é de $30^{\circ}$. Isto permite combinar o tempo de força do rotor com o tempo de força da bomba como descrito por Harwood (1980).

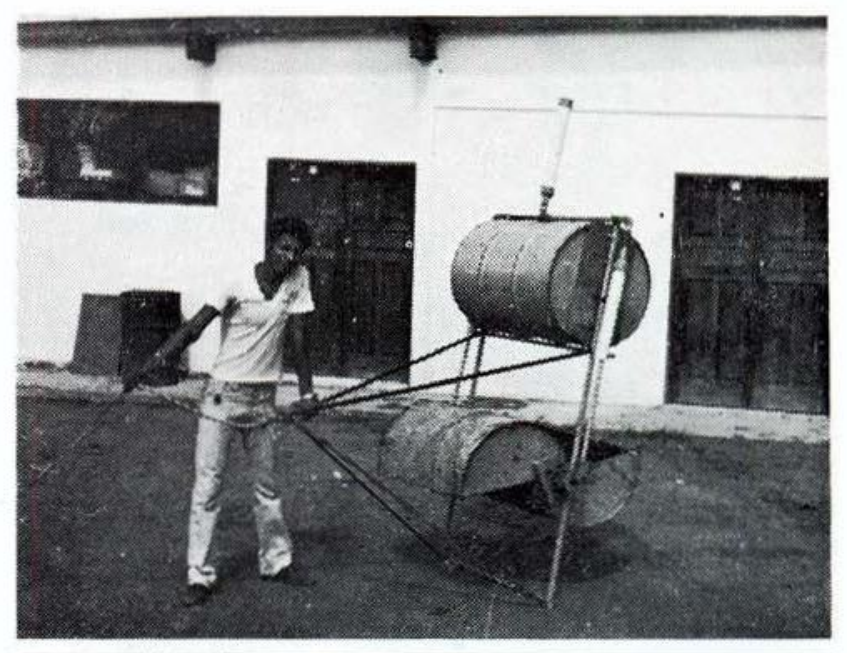

Fig. 1 - Bomba acionada por um rotor Savonius submerso, vista geral.

(1) - Instituto Nacional de Pesquisas da Amazônia, Manaus .

(2) - Zoology Dept., Linacre College, Oxford, Inglaterra. 
TABELA 1 - Lista dos materiais utilizados na construção da bomba

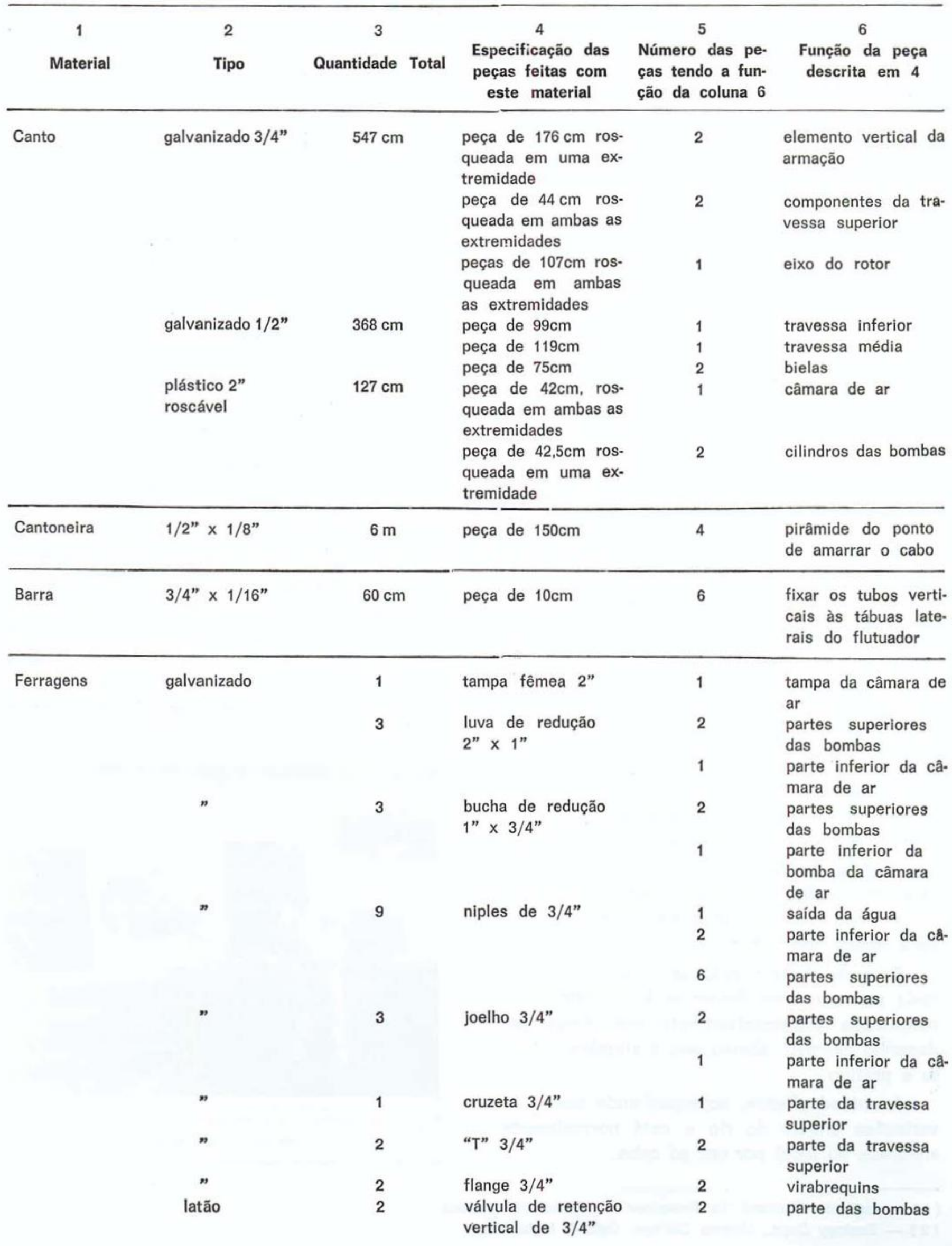


TABELA 1 - (Continuação)

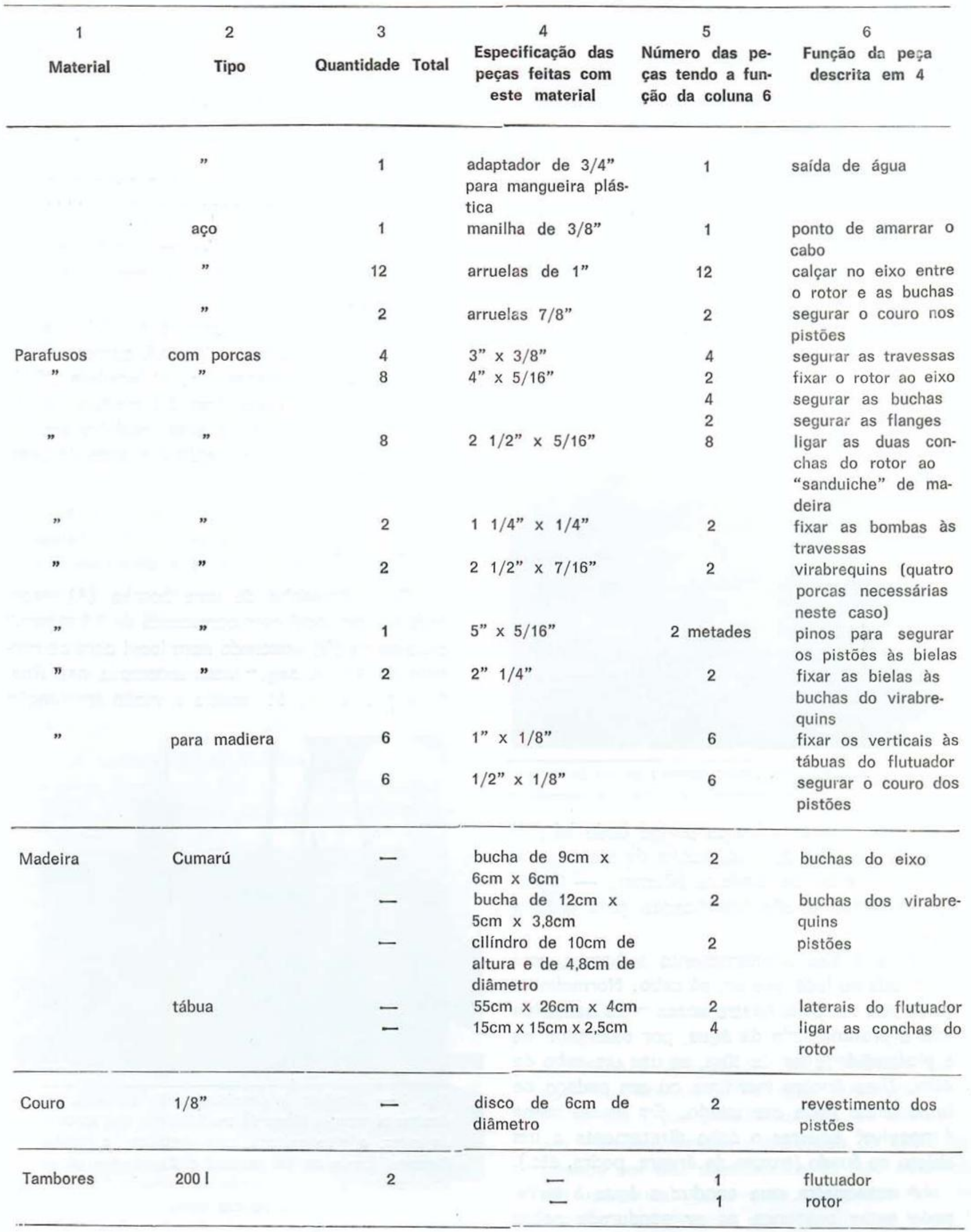




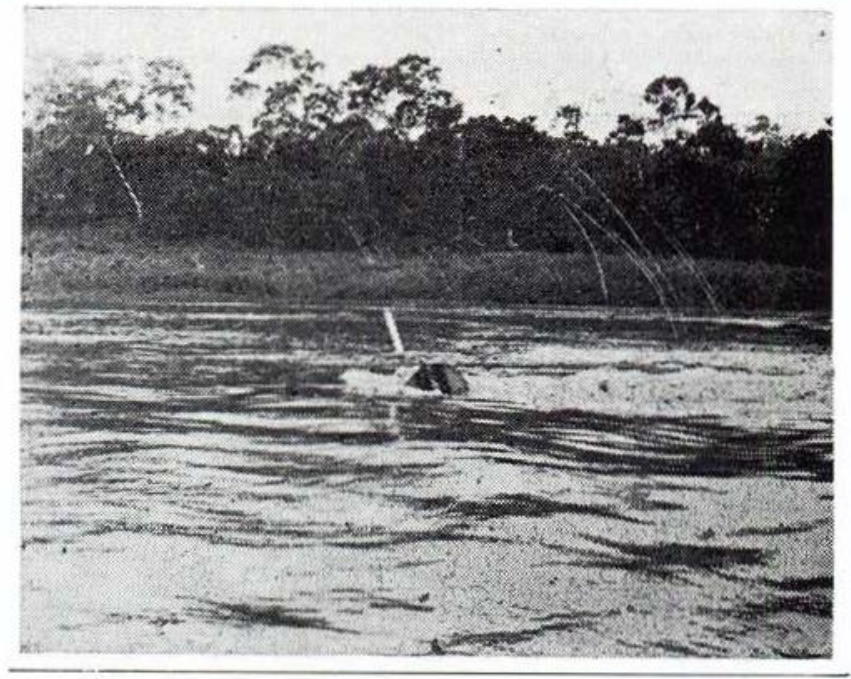

Fig. 2 - Bomba acionada por um rotor Savonius submerso. Protótipo ancorado no rio Solimōes, perto do Caldeirão.

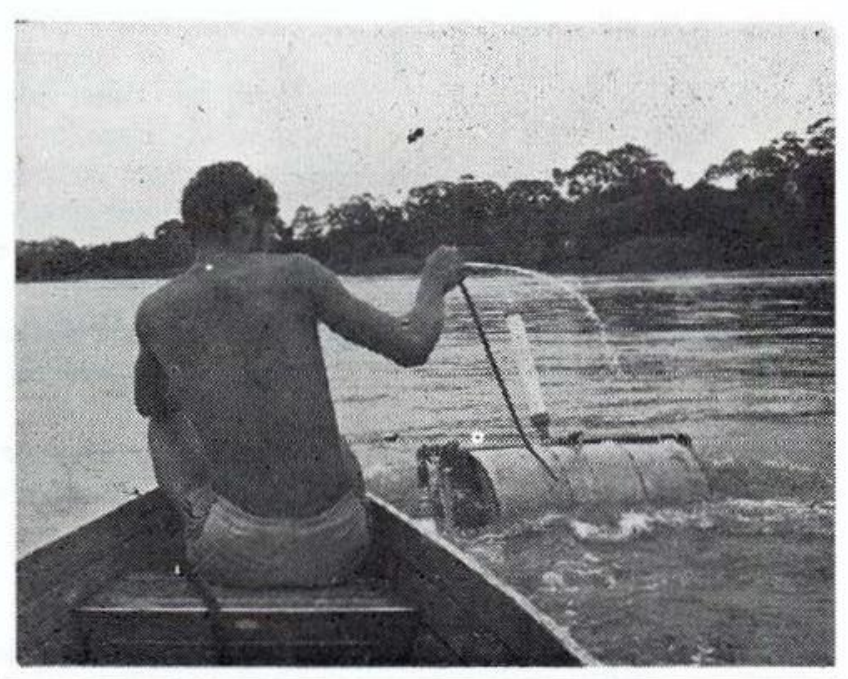

Fig. 3 - A bomba em funcionamento no rio Solimōes.

Como se vê, todas as partes onde há movimento (bucha do eixo, bucha da biela e pistão) são feitas de madeira (Cumaru - Dipteryx odorata) e são lubrificadas pela própria água.

Para o seu funcionamento a bomba está amarrada no local por um só cabo. Normalmente se usa um cabo quatro vezes mais comprido que a profundidade da água, por exemplo: se a profundidade for de $10 \mathrm{~m}$, se usa um cabo de $40 \mathrm{~m}$. Uma âncora marítima ou um pedaço de ferro velho pode ser usado. Em águas rasas é possivel amarrar o cabo diretamente a um objeto no fundo (trorico de árvore, pedra, etc.).

A mangueira, que conduz a água à terra, pode estar suspensa no ar pendurada sobre uma árvore conveniente, ou pode descer pelo cabo da âncora e atravessar o leito do rio.

O desempenho da bomba foi medido observando-se a sua vazão com várias pressões na saíde da água. Esta pressão foi mantida constante usando-se um registro e um manômetro ligados à saída.

A potência $P$ (Watts) utilizada no bombeamento foi calculada segundo a equação :

$\mathrm{P}=\mathrm{mgh} / \mathrm{t} \ldots \ldots \ldots \ldots \ldots \ldots \ldots \ldots \ldots$ (1) onde $\mathrm{m}$ quilogramas é a massa de água bombeada a uma altura de $\mathrm{h}$ metros em $\mathrm{t}$ segundos e g é a aceleração devida à gravidade (9.81 $\mathrm{m} \cdot \operatorname{seg} \cdot{ }^{-2}$ ) .

A velocidade da correnteza foi medida usando um medidor do tipo AA current meter (Scientific Instruments Inc. Milwaukee USA). A velocidade da correnteza foi medida não só durante as experiências mas também em outros lugares para ver a aplicabilidade da bomba à região.

\section{RESULTADOS}

O desempenho de uma bomba (A) ancorada em um local com correnteza de $0,6 \mathrm{~m} . \mathrm{seg}^{-1}$ e de outra (B) ancorada num local com correnteza de $1.1 \mathrm{~m} . \mathrm{seg}^{-1}$ está mostrada nas figs. 11 e 12. A fig. 11 mostra a vazão em função

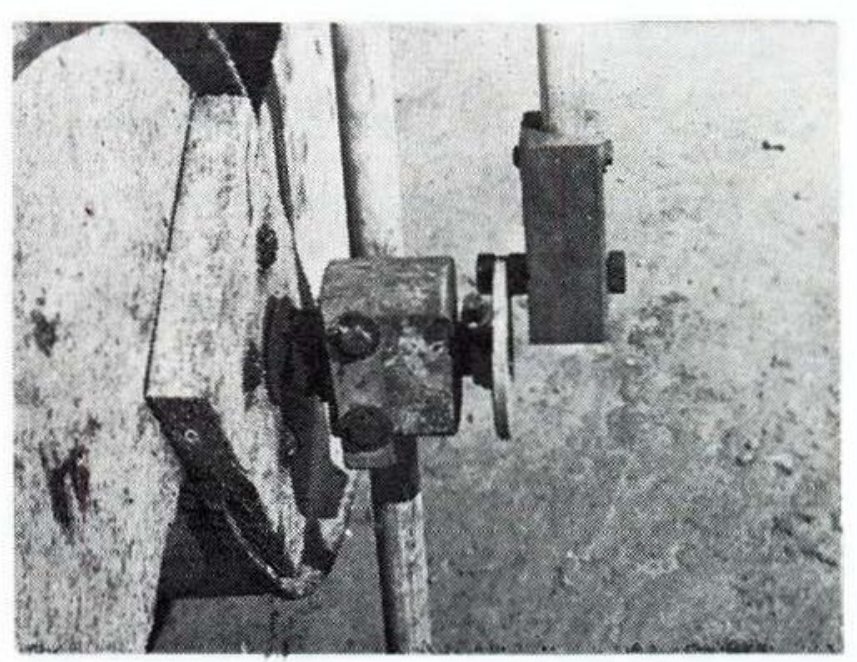

Fig. 4 - Detalhes da construção. Da esquerda para a direita: o rotor; a tábua de madeira que liga as conchas do rotor; o eixo calçado com arruelas; a bucha de Cumaru, fixado ao pé vertical o flange que serve de virabrequim; a biela da bomba com uma bucha de Cumaru na sua base. 
da pressão da saída. A fig. 12 mostra a potência utilizada no bombeamento em função do mesmo variável.

Pode ser visto que as duas bombas desenvolverarn a potência máxima quando a pressão na saída correspondia a uma altura de $28 \mathrm{~m}$. A esta pressão a bomba $(A)$ na correnteza de $0,6 \mathrm{~m}$. seg. ${ }^{-1}$ bombeou 2.100 litros de água por dia enquanto a bomba (B) na correnteza de 1,1 m.seg. ${ }^{-1}$ bombeou 3.100 litros por dia.

A leve diminuição da vazão da bomba B a baixas pressões é provavelmente devida ao mau fechamento das válvulas sem pressão adequada, um fenômeno freqüentemente observado com bombas de construção simples.

A pressão máxima desenvolvida pela bomba $A$. (na correnteza de $0,6 \mathrm{~m} . \mathrm{seg} \cdot{ }^{-1}$ ) era de $35 \mathrm{~m}$ de água e a da bomba $B$ (na correnteza de $1,1 \mathrm{~m} . \mathrm{seg} .^{-1}$ ) $\in$ ra de $43 \mathrm{~m}$ de água.

No ponto em que as bombas trabalham con ímáximo desempenho (pressão de $28 \mathrm{~m}$ de água) a eficiência global da bomba $A$ era de $8 \%$ enquanto a da bomba B era de $2 \%$ (comparando a energia no bombeamento com a energia no fluxo de água passando pelo rotor).

$A$ bomba $A$ foi testada em operação contínua sem problemas durante 3 meses. A bomba $B$ também não deu problema, mas foi retirada da água para fins didáticos.

A velocidade do rio Solimões, em vários lugares perto de Manaus está registrada na tabeia 2. Em todos os locais investigados a

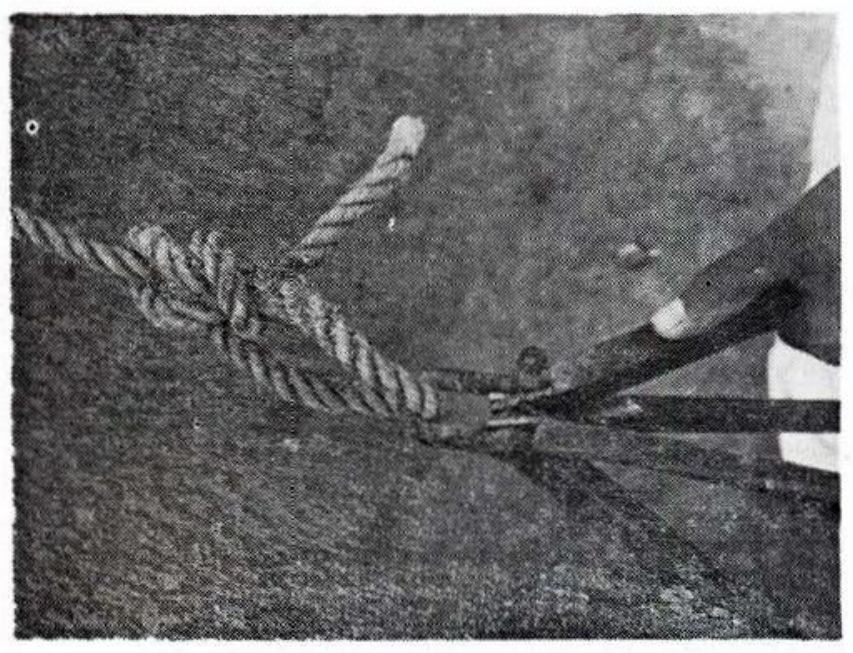

Fig. 5 - O ponto de fixação do cabo da âncora.

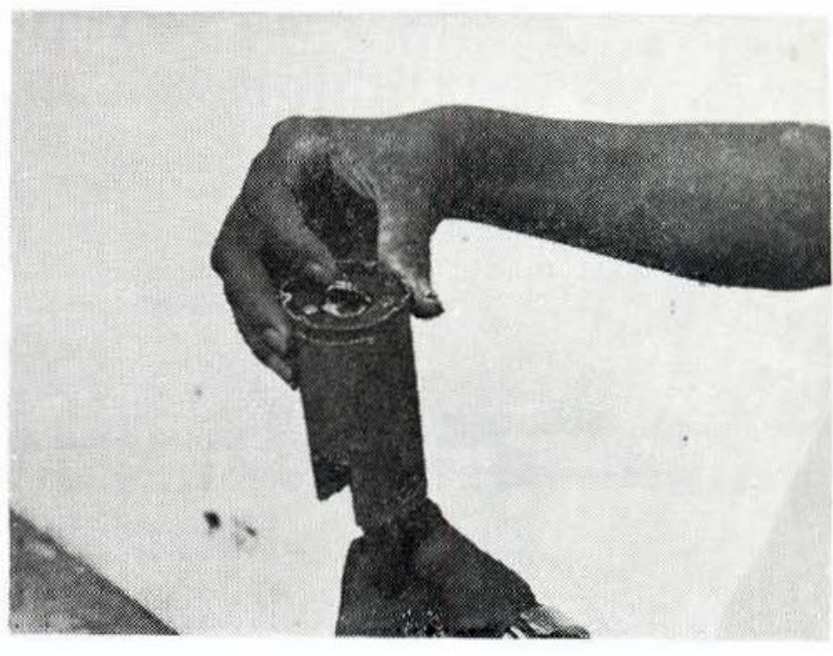

Fig. 6 - O pistão da bomba, feito em Cumaru. O revestimento de couro contém uma porta que serve de válvula, abrindo e fechando um furo central no pistão.

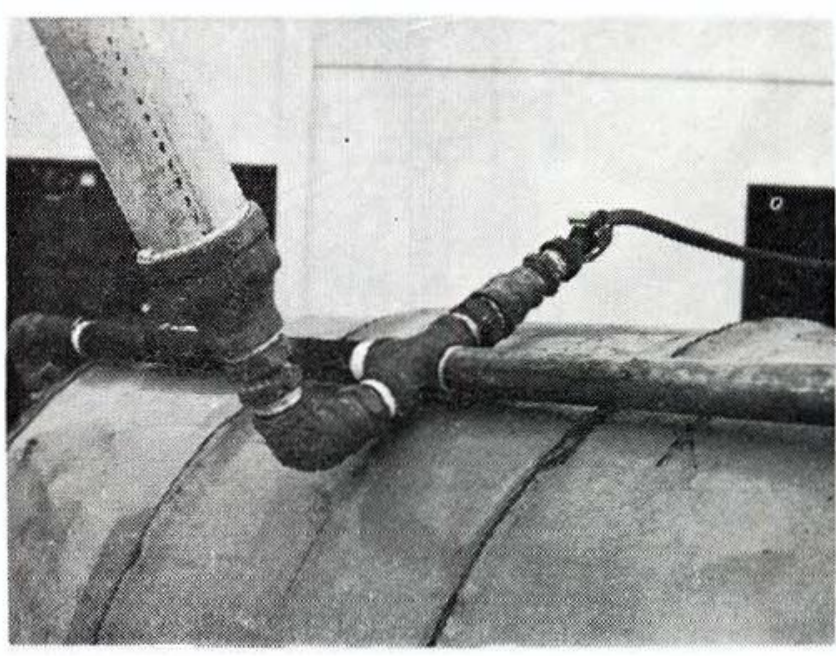

Fig. 7 - A câmara de ar e a saída da água.

correnteza foi superior a $0,6 \mathrm{~m} . \mathrm{seg} .^{-1}$ isto é, acima do mínimo necessário para acionar a bomba.

\section{DISCUSSÃo}

\section{SUPRIMENTO DE ÁGUA}

Mann \& Williamson (1973) indicam que o consumo doméstico de água raramente ultrapasse 225 I. por pessoa por dia. Se admitimos um consumo bastante generoso de 200 I. por pessoa por dia, uma bomba do tipo estudado, em um local com uma correnteza de 0,6 m.seg. ${ }^{-1}$. abasteceria uma família de 9 ou 10

Bomba... 


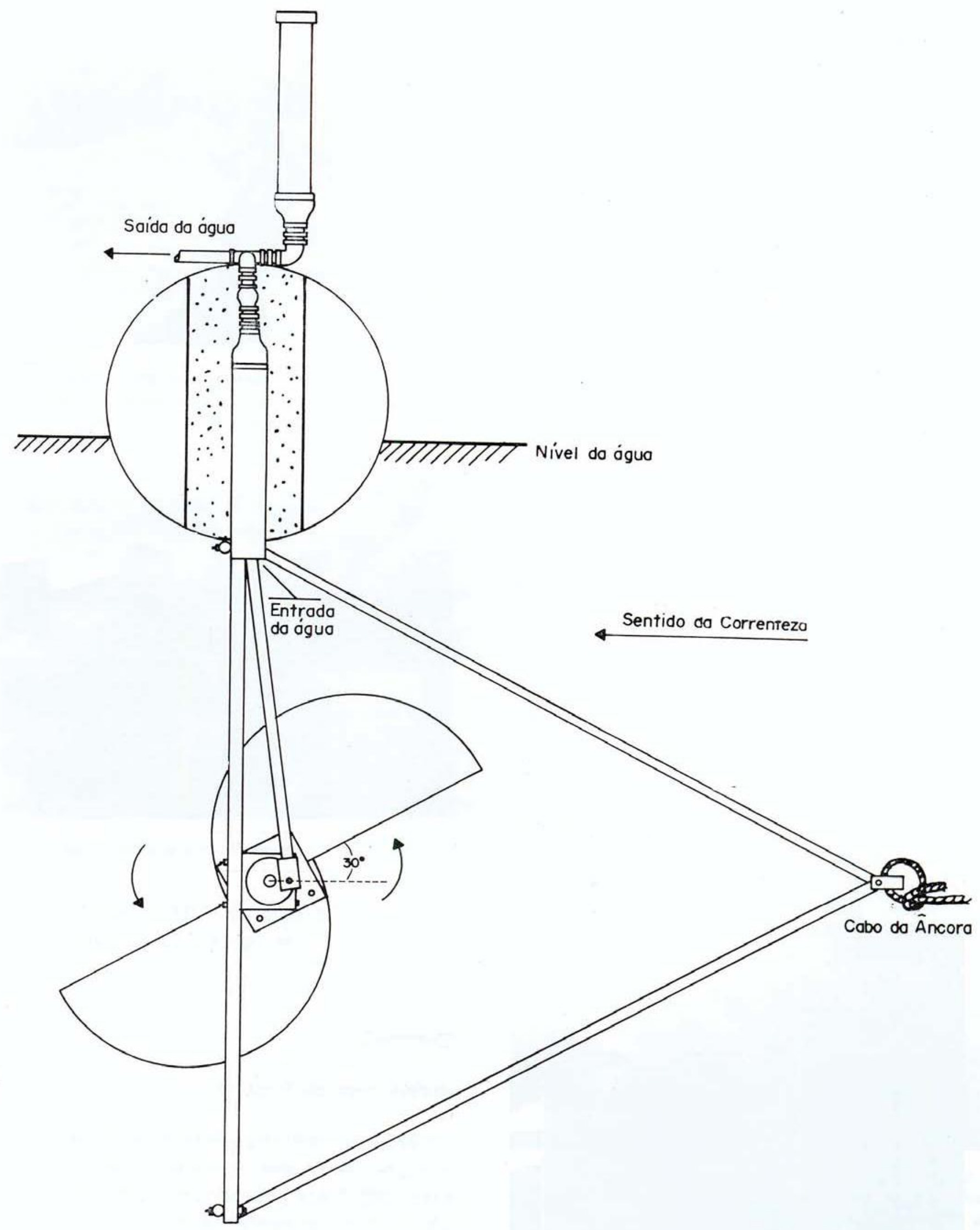

Fig. 8 - Bomba acionada por um rotor Savonius submerso. Vista lateral. Escala, aprox. 1:11 


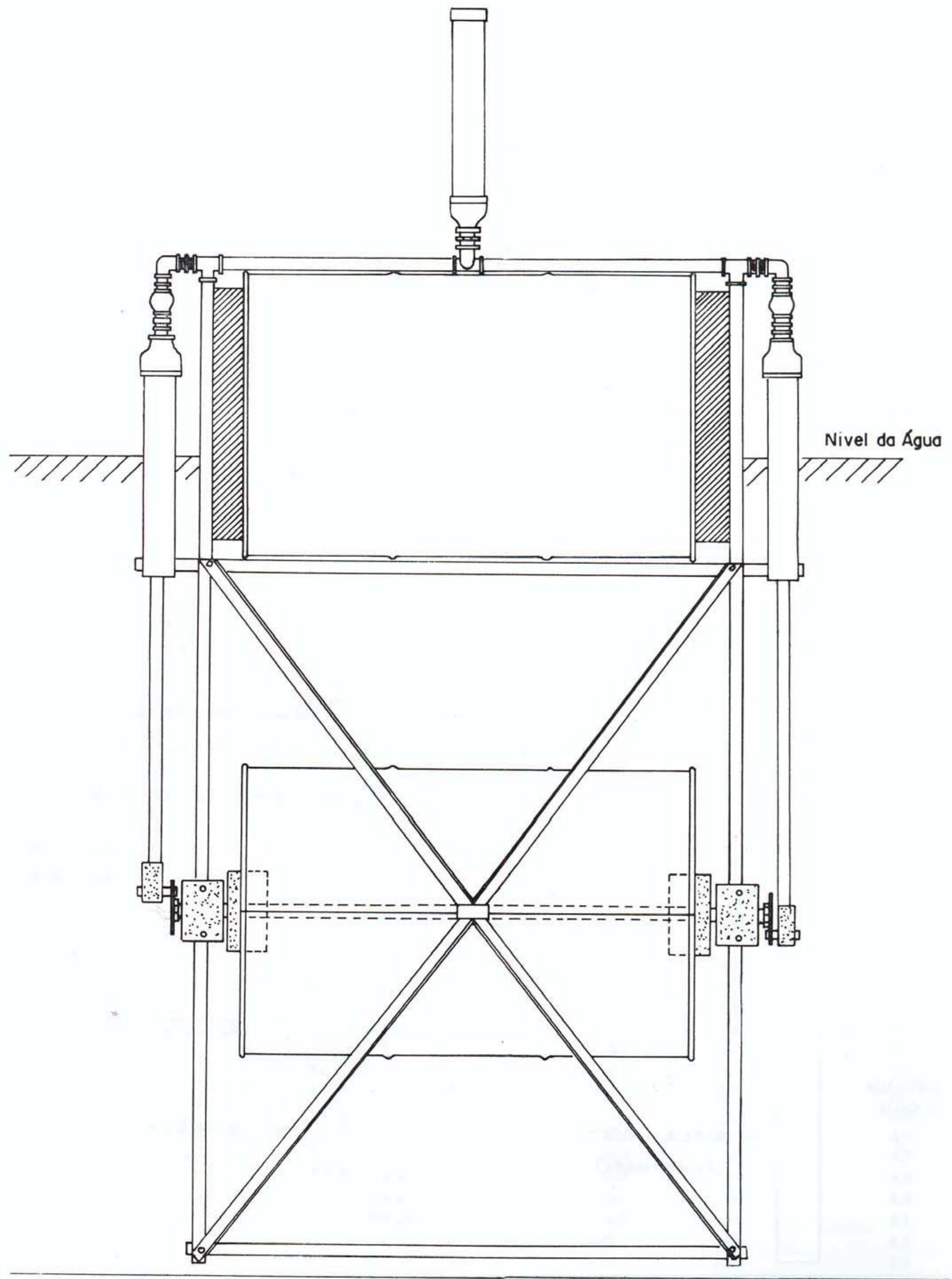

Fig. 9 - Bomba acionada por um rotor Savonius submerso. Vista frontal. Escala, aprox. 1:11. 


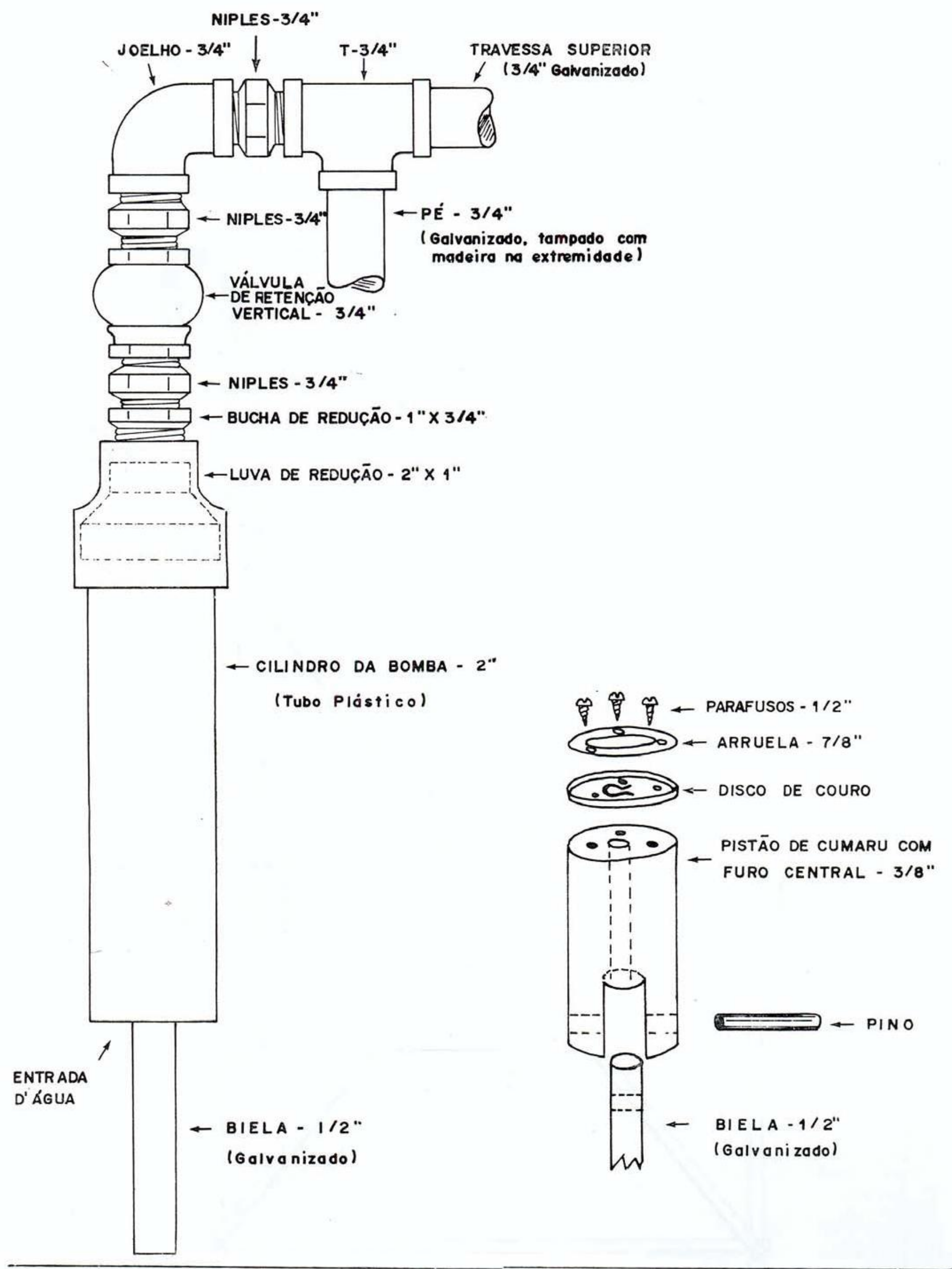

Fig. 10 - Detalhes da construção da bomba. 


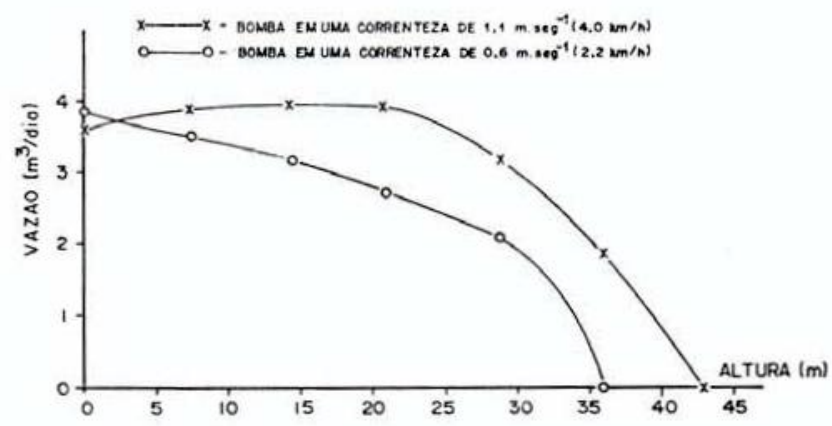

Fig. 11 - Vazão de duas bombas em função da pressão da saída d'água.

pessoas morando a $30 \mathrm{~m}$ acima do nível do rio. Naturalmente, se a correnteza estiver maior, ou a altura da casa menor, a bomba poderia fornecer água para mais pessoas.

\section{EFICIÊNCIA DO ROTOR}

Nota-se dos resultados que a vazão da bomba em uma correnteza de $1,1 \mathrm{~m} . \mathrm{seg} \cdot{ }^{-1}$ não é muito maior do que em uma correnteza 0,6 m.seg. ${ }^{-1}$. Esta observação está de acordo com a observação de Harwood (1980) que a eficiência do rotor cai dramaticamente com aumento da velocidade de água. Praticamente este fato impiica que não tem grande vantagem em buscar uma correnteza muito rápida.

Desta maneira, a bomba pode ficar nas águas menos movimentadas perto da margem onde ela estará mais protegida de detritos flutuantes e da navegação. Além disso, os cabos e mangueiras estarão mais curtos e a ancoragem mais fácil.

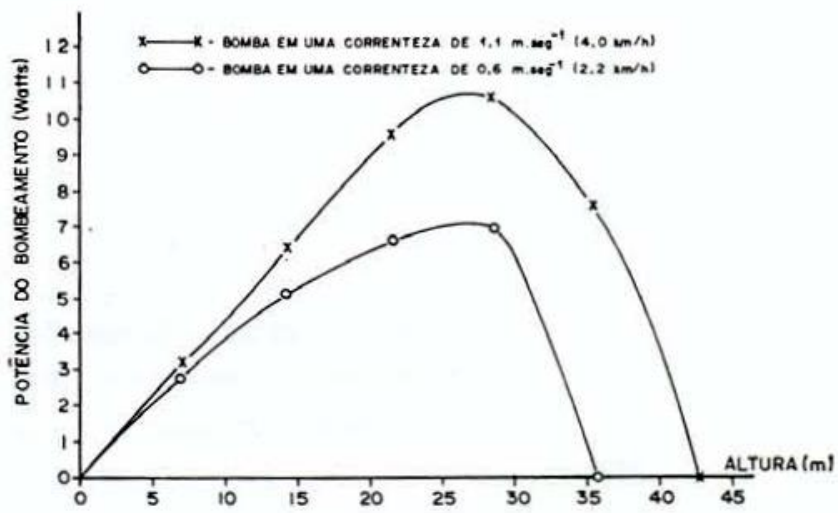

Fig. 12 - Potência desenvolvida por duas bombas bombeando a várias alturas.

TABELA 2 - Velocidade do rio Solimões em vários lugares perto de Manaus.

\begin{tabular}{|c|c|c|c|c|}
\hline Data & Local & $\begin{array}{l}\text { Profundidade } \\
\text { metros }\end{array}$ & m.seg..$^{-1}$ & Velocidade \\
\hline 22.05 .80 & Perto do canal Paracuuba, perto da beira & 7,6 & 0,75 & 2,7 \\
\hline$"$ & $" \quad n \quad " \quad " \quad$ & 6,1 & 0,66 & 2,3 \\
\hline$"$ & $" \quad$ meio do rio & 21,3 & 1,20 & 4,3 \\
\hline$n$ & $n \quad " \quad n$ & 21,3 & 1,65 & 5,9 \\
\hline$n$ & $\begin{array}{l}n \quad n \quad \begin{array}{l}\text { à margem da llha } \\
\text { dos Mouras }\end{array}\end{array}$ & 12,1 & 0,88 & 3,2 \\
\hline$n$ & $\begin{array}{lllll}n & n & n & n\end{array}$ & 12,1 & 0,64 & 2,3 \\
\hline 17.09 .80 & Caldeirão, perto da margem & 8,2 & 0,61 & 2,2 \\
\hline 18.03 .81 & $" \quad 50 \mathrm{~m}$ da margem & 14,0 & 0,88 & 3,2 \\
\hline 03.10 .80 & perto da margem & 18,3 & 1,04 & 3,7 \\
\hline 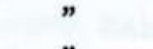 & $" \quad$ perto das pedras & 3,7 & 0,79 & 2,8 \\
\hline$"$ & $" \quad$ perto da margem & 7,6 & 0,71 & 2,5 \\
\hline$n$ & Ilha da Paciência, perto da margem & 8,2 & 0,86 & 3,1 \\
\hline$"$ & $n \quad n \quad n \quad n$ & 13,7 & 1,00 & 3,6 \\
\hline$"$ & Caldeirão, meio do rio & 23,1 & 1,17 & 4,2 \\
\hline 10.12 .80 & $" \quad n$ & 21,3 & 1,33 & 4,7 \\
\hline 28.04 .81 & Paraná do Careiro, $50 \mathrm{~m}$ da margem & 16,6 & 1,12 & 4,0 \\
\hline - & $" \quad n \quad$ meio do canal & 18,0 & 1,28 & 4,6 \\
\hline - & Costa do Rebojo, perto da margem & 8,0 & 1,14 & 4,1 \\
\hline- & $n \quad n$ meio do rio & $>25$ & 2,43 & 8,7 \\
\hline - & $n \quad n$ & $>25$ & 2,24 & 8,0 \\
\hline - & $"$ & $>25$ & 2,1 & 7,6 \\
\hline
\end{tabular}


O levantamento do recurso (cálculo de quantos rios na Amazônia tem correnteza adequacia ao funcionamento desta bomba) ainda não foi feito. Contudo, o rio Solimões se mostrou aproveitávei em todos os locais investigados perto de Manaus. É muito provável que seja adequado em toda a sua extensão, possi. bilitando assim a instalação de milhares de bombas.

\section{DIVULGAÇÃo}

Detalhes da bomba já foram entregues à EMATER-AM, CODEAGRO (AM), Secretaria de Indústria, Comércio e Turismo (MT) e à CEPA (RO). É de se esperar que, com a ajuda dessas empresas pode fazer-se um programa bem sucedido de divulgação desta máquina na região amazônica.

\section{AgRAdeCIMENToS}

Os autores agradecem à Fundação Ford, Rio de Janeiro, pelo apoio financeiro que permitiu a execução deste trabalho.
The construction of a pump powered by river currents using a submerged Savonius rotor is described in detail. The design is very simple, so that anybody can construct the pump using hand tools. The cost of materials for the unit is aproximately USS 70,00 . There is a slight variation in the performance of pumps of this type due to the rustic construction. Nevertheless, at maximum power a pump installed in a current of 0,6 m.seg.-1 $(2,2 \mathrm{~km} / \mathrm{h})$ pumped 2100 litres of water per day with a head of $28 \mathrm{~m}$. Another pump installed in a current of $1,1 \mathrm{~m} . \mathrm{seg} .^{-1}(4,0 \mathrm{~km} / \mathrm{h})$ pumped 3100 litres with the same head. At lower pressures the pumping rate increased to between 3500 and 3900 litres per day. Since the pump can improve the domestic comfort of the rural riversidade population and/or supply water for other purposes it is hoped that the design will be widely popularised. Contacts with Government bodies are being developed with this aim.

\section{REFERENCIAS BIBLIOGRAFICAS}

HARWOOD, John H.

1980 - Comparação de três rotores feitos localmente com eixos em diferentes dimensões extraindo energia cinética hidráulica dos rios amazônicos. Acta Amazonica, 10 (1): 167-177.

MANN, H.T. \& WILLIAMSON, D.

1973 - Water Treatment and Sanitation. Intermediate Technology Publications, London, (9).

(Aceito para publicação em $30 / 11 / 81$ ) 